\title{
Os Enfoques Cognitivista e Desenvolvimentista no Autismo: Uma Análise Preliminar
}

\author{
Carolina Lampreia ${ }^{1}$ \\ Pontifícia Universidade Católica do Rio de Janeiro
}

\begin{abstract}
Resumo
A imprecisão do conceito de autismo pode ser vista pela diversidade de quadros clínicos que entram neste conceito, assim como pelos diferentes enfoques teóricos que procuram explicá-lo. Desde a descrição de Kanner, o autismo tem sido visto ora como um problema afetivo/social, ora como um problema cognitivo. Nas décadas 1970/80, alguns autores consideraram o prejuízo social como primário no autismo enquanto outros defenderam o prejuízo da habilidade cognitiva da linguagem. Este debate mostrouse inconclusivo. Hoje predominam dois enfoques teóricos: o cognitivista e o desenvolvimentista que resgata a visão de autismo como um problema afetivo/social e dissolve a oposição social x linguagem na medida em que um de seus pressupostos epistemológicos é conceber a linguagem verbal como uma atividade social cujos precursores são encontrados nas comunicações não-verbais mãe-bebê. O objetivo deste artigo é iniciar uma reflexão a respeito da relevância do esclarecimento dos pressupostos epistemológicos e das implicações de diferentes enfoques teóricos do autismo para a busca da etiologia e para a intervenção. Palavras-chave: Autismo; cognitivismo; desenvolvimentismo.
\end{abstract}

\section{A Prelimary Analysis of Cognitive and Developmental Approaches in Autism}

\begin{abstract}
The diversity of clinical pictures and different theoretical approaches may explain the blurred boundaries of the concept of autism. Since Kanner, autism has been explained either as a social/affective deficit or a cognitive one. In the fruitless debate of the $1970 / 80$ s, some authors argued that the primary deficit was social/affective while others that it was in the cognitive area of language. Today the cognitive and developmental approaches predominate. The latter revives the social/affective approach to autism and dissolves the social $\mathrm{x}$ language opposition. One of its epistemological assumptions is to view language as a social activity because its precursors can be found in the mother-infant nonverbal communications. The purpose of this article is to begin a discussion about the importance of the epistemological assumptions of the different theoretical approaches to autism for the search of its etiology and intervention.

Keywords: Autism; cognitivism; developmentalism.
\end{abstract}

O conceito de autismo é um conceito, ainda nos dias de hoje, de contorno bastante impreciso, imprecisão esta que pode se dar em diferentes níveis. Por um lado, quanto às características comportamentais, podemos encontrar, diagnosticadas como autistas, crianças que falam e outras que não falam; crianças com pouco ou nenhum tipo de contato social e outras com um tipo bizarro de relacionamento; crianças com deficiência mental e outras com um nível de desenvolvimento adequado para sua idade. Esta heterogeneidade também está refletida no próprio DSM-IV (APA, 1995) a partir do qual pode-se tirar pelo menos 96 quadros clínicos diferentes se combinarmos dois critérios de interação social, um critério de comunicação e um de padrões restritos e repetitivos. Tendo em vista que existem quatro sub-itens relativos a cada uma dessas três categorias de avaliação, através de uma análise combinatória chega-se ao resultado de 96 combinações possíveis. E isto, sem levar em conta os

\footnotetext{
${ }^{1}$ Endereço para correspondência: Departamento de Psicologia PUC - Rio, Rua Marquês de São Vicente, 225, 22453 900, Rio de Janeiro, RJ. E-mail: lampreia@psi.puc-rio.br
}

outros dois itens requeridos para se chegar aos seis itens exigidos para o diagnóstico, o que elevaria em muito o número de combinações possíveis. Sem um conhecimento da etiologia, ou possíveis etiologias, ficamos limitados a uma tentativa de definição do autismo a partir das características comportamentais.

Outro nível de imprecisão do conceito envolve diferentes concepções de autismo em termos de enfoque teórico - desenvolvimentista ou cognitivista - que invocam diferentes prejuízos primários - social ou linguagem, por exemplo. Segundo a visão cognitivista, o prejuízo primário no autismo deve ser encontrado em um dos diversos módulos da mente. No passado, esta visão considerou que o módulo afetado era principalmente o da linguagem, enquanto que, nos dias atuais, predomina a idéia de que o módulo responsável pela teoria da mente é que está prejudicado. Segundo a visão desenvolvimentista, o quadro autístico se deve a um desvio do desenvolvimento que tem em sua origem um ou diversos transtornos de cunho biológico, ainda não esclarecidos, que afetam basicamente a afetividade e capacidade geral de relacionamento social, impedindo assim o desenvolvimento de forma típica. 
Nos anos 1970/80, deu-se um importante debate sobre qual seria o prejuízo primário no autismo, prevalecendo duas posições vistas como antagônicas. A primeira defendia um prejuízo do relacionamento social que prejudicaria o desenvolvimento da linguagem, enquanto a segunda defendia um problema mais básico na área da linguagem que prejudicaria a interação social. Seria possível argumentar que esta polarização talvez não faça sentido na medida em que podemos considerar que está implícita, no conceito de interação social, a idéia de comunicação e que nesta está implícito o conceito de interação social. Ou seja, seria possível argumentar que, por definição, não há linguagem/comunicação sem interação social. assim como não há interação social sem comunicação. Contudo, esta argumentação pode não ser tão óbvia quanto parece ser.

Embora este tipo de debate não seja mais predominante na literatura atual, torna-se importante revê-lo por duas razões. Em primeiro lugar, para analisar e tentar esclarecer os conceitos de social e linguagem no autismo. Parece haver uma certa imprecisão quanto a estes conceitos, na medida em que comportamentos de comunicação nãoverbal, como gestos, podem ser também concebidos como comportamentos sociais, como o faz o DSM-IV (APA, 1995). Em segundo lugar, este tipo de debate também permite refletir sobre a possível dissolução das oposições teóricas subjacentes às posições adotadas. Aqueles que defendem um prejuízo primário da linguagem costumam adotar um enfoque cognitivista, enquanto os defensores de um prejuízo social adotam, principalmente nos dias atuais, um enfoque desenvolvimentista que concebe os problemas de interação social como decorrendo de uma falha muito básica na capacidade de expressividade e responsividade emocional/afetiva. Em outras palavras, a discussão dos conceitos de interação social e linguagem está intimamente relacionada à discussão dos pressupostos teóricos envolvidos. $\mathrm{E}$ isto tem implicações para o próprio conceito de autismo, que não pode ser definido apenas a partir de características comportamentais, assim como também para a intervenção.

O objetivo deste artigo é iniciar uma reflexão a respeito da relevância do esclarecimento dos pressupostos epistemológicos e das implicações de diferentes enfoques teóricos do autismo para a busca da etiologia e para a intervenção. Isto será feito inicialmente a partir de uma discussão dos conceitos de interação social e linguagem no autismo, visando uma análise crítica das posições cognitivista e desenvolvimentista.

Em um primeiro momento, será apresentado o histórico dos posicionamentos teóricos para em seguida rever o debate das décadas 1970/80. Finalmente, será apresentada a posição desenvolvimentista atual e como conclusão será avaliado o alcance de suas implicações.

\section{Histórico dos Posicionamentos Teóricos}

Ao longo dos anos, desde a primeira formulação da síndrome descrita por Kanner (1943), o autismo tem sido visto, predominantemente, ora como um distúrbio social/ afetivo, ora como um distúrbio cognitivo. Três fases podem ser discriminadas neste sentido ${ }^{2}$. Na primeira fase, a da formulação inicial de Kanner, o autismo é visto como um distúrbio de contato afetivo. O desligamento de relações humanas, antes dos 12 meses de idade, é uma das cinco categorias discriminadas, no seu estudo de 1943, para definir o autismo junto com a falha no uso da linguagem para a comunicação, a manutenção da rotina, a fascinação por objetos e as boas potencialidades cognitivas (Eisenberg \& Kanner, 1956). Em 1956, depois de efetuados estudos de follow-up, são isolados dois aspectos patognômicos : o autoisolamento extremo e a insistência obsessiva na preservação da rotina, que se manifestam nos dois primeiros anos de vida. Contudo, o problema principal estaria na área social quando é afirmado que "A principal patologia permanece na área da inhabilidade de se relacionar de maneira ordinária com outros seres humanos", mencionando-se também a "surpreendente falta de consciência dos sentimentos dos outros" e a "falha em reconhecer os outros como entidades separadas de si mesmo" (Eisenberg \& Kanner, 1956, pp. 558-559). Em termos de etiologia, Kanner não considera que haja um agente etiológico único, sendo o quadro clínico produzido conjuntamente por fatores inatos e ambientais.

Na segunda fase, ao longo das décadas de 1970 e 80, o autismo passa a ser visto, predominantemente, como um distúrbio cognitivo. Nesta época, ele deixa de ser considerado como uma condição envolvendo basicamente retraimento social e emocional, e passa a ser concebido como um transtorno do desenvolvimento envolvendo déficits cognitivos severos com origem em alguma forma de disfunção cerebral. A observação da existência de déficits cognitivos leva à consideração de questões envolvendo, entre outros, processos de atenção, memória, sensibilidade a estímulos e linguagem. Neste sentido, por exemplo, Rutter (1976) focaliza a possível importância do prejuízo da linguagem, ao considerar esta anormalidade como um aspecto central do déficit cognitivo associado ao autismo, passando a desenvolver pesquisas nesta área (Ex.: Bartak, Rutter \& Cox, 1975).

${ }^{2}$ Green, Fein, Joy eWaterhouse (1995), Klinger e Dawson (1992), Rutter (1976) e Waterhouse, Wing e Fein (1989) apresentam alguma discussão e referências a respeito desta mudança de enfoque e as mudanças seguintes. 
Na terceira fase, a partir do final da década de 1980, vários autores passam a pesquisar em detalhe o prejuízo social e a adotar um enfoque desenvolvimentista. Sua posição é que a incapacidade inata de se relacionar com pessoas, isto é de responder emocionalmente aos outros, teria como uma de suas conseqüências o prejuízo do desenvolvimento da comunicação não-verbal e por conseguinte da linguagem. Alguns dos principais autores representativos desta posição são Trevarthen (Trevarthen, Aitken, Papoudi \& Robarts, 1998), Hobson (2002) e Dawson (Dawson \& Galpert, 1986; Dawson \& Lewy, 1989). Embora esta visão desenvolvimentista ganhe cada vez mais adeptos, ainda há autores, como por exemplo Frith (1997) e Baron-Cohen (2000), que defendem a visão cognitivista da Teoria da Mente. Segundo esta posição, autistas não possuem a habilidade de imaginar e compreender $\mathrm{o}$ estado mental dos outros, isto é, de ter uma teoria da mente, por terem o mecanismo cognitivo inato, responsável por esta habilidade, prejudicado. Por esta razão, têm seu comportamento social afetado.

As diferentes posições envolvidas neste debate concordam que na base do autismo encontra-se um prejuízo biológico que seria responsável pelas características comportamentais, sobre as quais também há concordância. Contudo, elas diferem principalmente, como visto, em seu enfoque teórico: cognitivista $\mathrm{x}$ desenvolvimentista. $\mathrm{E}$ isto tem implicações para a conceituação do autismo. Uma das possíveis formas para se pensar a imprecisão deste conceito é procurar esclarecer a dicotomia social x linguagem.

\section{O Debate sobre o Prejuízo Primário no Autismo}

Será apresentado aqui o debate ocorrido em 1970/80. Primeiro serão considerados os argumentos em favor de um prejuízo primário da linguagem e, em seguida, os argumentos do prejuízo primário da interação social. Em cada uma dessas partes, serão vistos inicialmente os prejuízos mais característicos e, em seguida, os argumentos em favor de ser o prejuízo primário. Finalmente, serão vistas algumas considerações que procuram relativizar a oposição social/ linguagem.

\section{O prejuízo da linguagem}

Inúmeras crianças autistas - cerca de 50\% - nunca fazem uso da fala e aquelas que falam apresentam anormalidades (Rutter, 1978). Os prejuízos nas habilidades lingüísticas e pré-lingüísticas no autismo envolvem não apenas um atraso mas, principalmente, um desvio no curso do desenvolvimento. No autismo, o desenvolvimento das habilidades lingüísticas é muito diferente do desenvolvimento das crianças ditas 'normais' e daquelas que apresentam desordens da linguagem.
O prejuízo lingüístico no autismo envolve problemas de comunicação não-verbal, problemas simbólicos, problemas de fala, assim como problemas pragmáticos. Há falhas em habilidades que precedem a linguagem como o balbucio, a imitação, o uso significativo de objetos e o jogo simbólico. Há também falhas na compreensão da fala, falta de gestos, mímica e do apontar.

Stone, Ousley, Yoder, Hogan e Hepburn (1997) afirmam que, no primeiro ano de vida, os bebês "normais" aprendem a se comunicar não-verbalmente através do contato ocular, vocalizações e gestos pré-lingüísticos. Os autistas apresentariam um padrão desordenado do desenvolvimento da comunicação com déficits no uso e compreensão de formas não-verbais de comunicação, assim como uma amplitude limitada de comportamentos comunicativos nãoverbais, isto é, um uso menos freqüente de contato ocular, apontar e mostrar objetos.

Crianças autistas apresentam problemas em responder a comunicações não-verbais tais como gestos, expressões faciais, entonação (Garfin \& Lord, 1986), e a área de atenção compartilhada é uma das mais prejudicadas (Camaioni, Perucchini, Muratori \& Milone, 1997; Mundy \& Crowson, 1997; Mundy \& Sigman, 1989).

Problemas no desenvolvimento do apontar, mostrar e imitar, especialmente se combinados com estereotipias e jogo simbólico deficiente, apontam para um diagnóstico de autismo em vez de transtorno do desenvolvimento da linguagem ou retardo (Rapin, 1996). Uma pesquisa relatada por Rapin encontrou que o jogo de faz-de-conta separou autistas de não-autistas. Esta autora considera, então, que o jogo simbólico é um bom marcador do autismo e pode servir de critério de diagnóstico em crianças com atraso cognitivo com suspeita de autismo.

Com relação aos aspectos pragmáticos da linguagem, há prejuízo da compreensão e uso da linguagem, dentro de um contexto social, mas não necessariamente do significado literal. Embora os acompanhamentos não-verbais da fala normal - expressão facial, contato ocular, postura corporal, gestos, mímica - quase sempre estejam afetados, Shah e Wing (1986) e Wing (1988) consideram que o "prejuízo social" consiste em dificuldades no uso espontâneo de sistemas verbais e não-verbais de comunicação, que tornam o intercâmbio social recíproco efetivo. O problema mais geral na comunicação não seria uma ausência dos mecanismos físicos de gesto, expressão facial e fala mas uma falha no uso correto em situações sociais ou como ajuda para a comunicação efetiva.

Rutter e Schopler (1988) também fazem referência aos prejuízos na área da linguagem mencionados pelos autores acima. Eles afirmam que: muito antes de falar, os bebês autistas não usam sons para se comunicar; há um déficit nas 
habilidades pré-verbais como o jogo simbólico ou de fazde-conta; os autistas não conseguem se comunicar através do uso de gestos, como as crianças surdas fazem; há falha em responder à comunicação dos outros e em sustentar uma conversa, além de haver uma falta de uso social das habilidades de linguagem possuídas.

Como mencionado anteriormente, Rutter (1976) é um dos que defendem a posição de que o prejuízo da linguagem é anterior ao prejuízo social. Este autor vai contra o argumento de Kanner (1943) de que é o retraimento social que leva aos problemas de linguagem, considerando que, ao contrário, o problema social parece estar vinculado ao problema de linguagem. Seu argumento é que o atraso na fala é uma condição quase invariável no autismo e que a linguagem é o fator de prognóstico mais importante, fora o QI. Cita também um estudo em que vários autistas deixaram de apresentar retraimento social mas permaneceram sem fala e tinham dificuldades em compreender instruções faladas, embora obedecessem a gestos e demonstrações. Sua conclusão é que a falha em falar se deve a uma falha básica em habilidades de linguagem e não à falta de motivação para falar ou o retraimento social (Rutter, 1968). Ele argumenta que o déficit na compreensão da linguagem em geral - o problema simbólico - e não especificamente o déficit da fala, parece ser primário e não secundário ao problema social. Para ele, a hipótese da linguagem oferece uma explicação que parece dar conta da maioria dos principais resultados, embora a natureza da anormalidade básica de linguagem permaneça desconhecida (Rutter, 1968, 1976). Em suma, o déficit cognitivo seria uma parte essencial do autismo e as anormalidades da linguagem, uma parte essencial desse déficit cognitivo (Rutter, 1976).

Wing também se posiciona a favor de um déficit mais básico na área da linguagem, embora focalize primordialmente em seu escritos a área social. Em um texto em que aborda a questão do possível prejuízo primário, Wing (1980) advoga em favor de problemas cognitivos que afetam a compreensão e o uso da linguagem, em quaisquer de suas formas. Ela afirma que, embora Kanner visse o isolamento social como um prejuízo primário, o isolamento é uma inferência feita pelo observador a partir de problemas cognitivos, de linguagem e de comunicação não-verbal que interferem seriamente com os intercâmbios sociais. Como argumento a favor de um problema mais básico de linguagem dando lugar a problemas na área social, Wing considera que crianças surdas, que apresentam isolamento social, perdem seu "autismo" quando aprendem métodos alternativos de comunicação. Por outro lado, crianças com desordem de desenvolvimento da fala receptiva, que apresentam algum comportamento autista, têm maior probabilidade de usar gestos e algum jogo simbólico. O diagnóstico diferencial entre distúrbio da fala receptiva e autismo seria o uso de símbolos.

Em suma, vários pesquisadores reconhecem déficits comunicativos muito precoces que podem ser vistos a partir de déficits no uso e compreensão da comunicação nãoverbal e na atenção compartilhada. Wing (1980) e Rutter (1976), que concebem o prejuízo lingüístico como sendo mais básico, argumentam que: o isolamento social é uma inferência a partir de problemas cognitivos e comunicativos; o prejuízo social consiste em dificuldades no uso da comunicação verbal e não-verbal; a falha na linguagem não se deve ao retraimento social, sendo o problema simbólico anterior ao problema social.

\section{O prejuízo da interação social}

A observação de vários desvios comportamentais desde o nascimento, ou pelo menos muito cedo no desenvolvimento inicial, tem levado inúmeros pesquisadores a inferir um transtorno em processos neurobiológicos específicos que prejudicariam o desenvolvimento social e emocional no autismo (Dawson \& Galpert, 1986; Mundy \& Sigman, 1989; Richer, 1976; Rutter, 1978; Rutter \& Schopler, 1988; Shah \& Wing, 1986).

Em termos mais gerais, dentre os déficits sociais, são mencionados a apreciação inadequada de deixas socioemocionais e a falta de reciprocidade socioemocional (Rutter \& Schopler, 1988), transtornos nas capacidades expressiva e receptiva iniciais e dificuldade para discriminar e compreender expressões faciais (Dawson \& Galpert, 1986), desordens específicas no desenvolvimento de comportamentos de comunicação não-verbal (Mundy \& Sigman, 1989).

Em termos mais específicos, tem sido mencionada a falta de aconchego no colo, de antecipação postural e de contato ocular. Foi observado também uma ausência de expressão facial, que o bebê raramente ri ou chora, e uma falta de imitação gestual (Dawson \& Galpert, 1986) e de gestos para regular a interação social (Rutter \& Schopler, 1988). Há uma falta de respostas às emoções dos outros (Rutter, 1978) sendo rara também a procura de outros para ter consolo e afeição (Rutter \& Schopler, 1988).

É importante sublinhar, neste momento, que nem todos os pesquisadores aqui mencionados, embora reconheçam falhas iniciais na área social, postulam o prejuízo social como sendo primário no autismo. Rutter (1968) por exemplo, como visto, é um dos que defendem um prejuízo primário de ordem cognitiva na área da linguagem, e Wing (Shah \& Wing, 1986), como será visto a seguir, na área da cognição social.

Shah e Wing (1986) apresentam uma discussão a respeito dos prejuízos cognitivos específicos subjacentes à interação social, e consideram haver a possibilidade dos autistas terem déficits específicos nas habilidades cognitivas subjacentes à 
percepção de pessoas e da interação social recíproca. As autoras consideram que está em aberto a questão de se esses déficits na cognição social são a causa subjacente das anormalidades do comportamento social e das relações interpessoais. E afirmam que a relação causal inversa também é uma possibilidade.

Em outro trabalho, Wing (1988) afirma que o problema central que, por definição, é tanto necessário como suficiente para o diagnóstico de uma desordem no continuum do espectro autista, é um prejuízo intrínseco no desenvolvimento da habilidade de se engajar em interação social recíproca. E Waterhouse, Wing e Fein (1989) consideram que os problemas de interação social são a base para todos os esquemas de diagnóstico.

Desta maneira, embora Wing não considere o problema de interação social como sendo primário no autismo, todo o seu trabalho se desenvolve em torno desta questão, chegando inclusive a propor um sistema de classificação do espectro autista baseado na qualidade da interação social - isolamento social, interação passiva, interação ativa mas bizarra (Wing \& Gould, 1979) - e a conceber o autismo a partir de uma tríade de prejuízos: 1) na interação social, com falhas no reconhecimento social; 2) da comunicação social, que afeta o dar e receber sinais verbais e não-verbais, pré-verbais sociais; 3) da imaginação e compreensão social que afeta a habilidade de copiar ações dos outros com compreensão de seu significado e objetivo, e interfere com o desenvolvimento do faz-de-conta e da teoria da mente (Wing, 1988). O prejuízo social passa a ser concebido mais como um critério essencial para o autismo do que um déficit primário.

Mas outros autores são mais específicos na defesa de um prejuízo social anterior ao prejuízo de linguagem, concebendo-o como uma desordem primária. Mundy e Sigman (1989) argumentam que os déficits sociais e emocionais são componentes fundamentais da desordem e não epifenômenos de disfunção cognitiva sendo que alguns dos primeiros tipos de déficit parecem ocorrer na expressão afetiva e comunicação não-verbal.

Walters, Barrett e Feinstein (1990) observam que o bebê humano é pré-programado para reconhecer emoções nos outros e para usar emoções para se comunicar, antes do desenvolvimento de outras formas de comunicação, e que há uso de evitação do olhar aos 6 meses para regular a ativação durante intercâmbios afetivos em situação face-a-face.

Hermelin e O'Connor (1985), em vez de considerarem a falha na ligação afetiva e a anormalidade cognitiva como problemas independentes, afirmam que o processamento cognitivo e lingüístico retêm muitas características anormais e peculiares, talvez como uma conseqüência do prejuízo afetivo. Os autores propõem a existência de uma disfunção lógico-afetiva que dá à sindrome sua qualidade peculiar. Para eles, o baixo nível de competência na compreensão de indicadores emocionais aponta para uma dificuldade específica com os sinais não-verbais que comunicam sentimentos. Esta conclusão seria apoiada pela ausência de gestos que expressam emoções em seu comportamento espontâneo.

Em suma, vários autores reconhecem um prejuízo social inicial, evidenciado principalmente por transtornos nas capacidades receptiva e expressiva iniciais. Mencionam, mais especificamente, uma apreciação inadequada de deixas socioemocionais, falta de reciprocidade socioemocional, ausência de expressão facial, dificuldade para discriminar e compreender expressões faciais. Mesmo aqueles pesquisadores, como Rutter e Wing, que não consideram o prejuízo social como sendo primário no autismo, endossam essas características. Aqueles que defendem o déficit social como primário argumentam basicamente que: o déficit de comunicação não-verbal é um tipo de déficit social; os problemas cognitivos e lingüísticos podem derivar do prejuízo afetivo; há uma falha no reconhecimento e uso de emoções para se comunicar antes do desenvolvimento de outras formas de comunicação. Em outras palavras, o déficit social é anterior aos problemas de comunicação.

\section{Relativizando a oposição social/linguagem}

Algumas ponderações precisam ser feitas de maneira a relativizar, em certa medida, a oposição social/linguagem. Em primeiro lugar, alguns autores observam que os prejuízos no autismo são mais qualitativos que quantitativos. Mundy e Sigman (1989), por exemplo, afirmam que o déficit de contato ocular pode ocorrer em alguns contextos mas não em outros e que crianças autistas respondem à estimulação social, sendo que o apego não está completamente ausente. Da mesma maneira, Cairns (1986) afirma que não há uma falha total da reciprocidade mas uma falha no nível, e espontaneidade, da reciprocidade normal.

Em segundo lugar, alguns autores observam uma correlação entre os prejuízos sociais e os de linguagem. Interpretando os dados do estudo de Camberwell, Wing (1981) observa que no grupo de crianças sociáveis todas compreendiam e usavam a comunicação não-verbal, e aquelas com compreensão da linguagem correspondente a 20 meses apresentavam jogo simbólico. Por outro lado, as crianças não-sociáveis não apresentaram comunicação nãoverbal nem jogo simbólico. Nestas não-sociáveis, os níveis de prejuízo da linguagem dependeram do subgrupo em que foram enquadradas - 'isoladas', 'passivas' ou 'ativas mas bizarras'. No estudo de Camberwell, o prejuízo social é paralelo ao prejuízo da função simbólica, isto é, as crianças 'isoladas' em sua maioria não tinham compreensão ou uso da linguagem, e não tinham jogo de faz-de-conta; as 'passivas' 
tinham alguma linguagem e algumas imitavam o faz-de-conta, enquanto as 'ativas mas bizarras' tinham alguma linguagem ou falavam (Wing, 1988)

Em terceiro lugar, alguns autores como Schopler e Mesibov (1986), defendem a não separação entre social e linguagem. Olley (1985) diz que comunicação é, por definição, um ato social, e Lord (1985) considera a linguagem uma habilidade social. Richer (1976) também concebe a linguagem como uma habilidade social, e por isso déficits sociais poderiam impedir o desenvolvimento da linguagem e competência comunicativa. Contudo, ele observa que o oposto também se aplica. Por isso, considera que pode ser frutífero estudar padrões de interação social dos autistas para ver que implicações eles podem ter tanto para a socialização quanto para a comunicação. Da mesma maneira, Garfin e Lord (1986) consideram a comunicação como um tipo de comportamento social e propõem que se discuta: a relação entre problemas de comunicação e problemas sociais; aspectos da comunicação relacionados mais diretamente ao funcionamento social; e elementos do desenvolvimento social que afetam a aprendizagem e uso das habilidades de comunicação. Por fim, Cairns (1986) afirma que é difícil imaginar que o desenvolvimento social proceda independentemente do desenvolvimento da linguagem ou vice-versa. Ele observa que a construção teórica, relevante a esses dois domínios, tem progredido como se os teóricos vivessem em terras diferentes. Para este autor, a convergência das disfunções sociais e de linguagem no autismo pode proporcionar um novo insight para a questão mais ampla de como esses domínios podem ser integrados teoricamente. E isto parece estar presente nas propostas de alguns autores desenvolvimentistas.

\section{A Visão Desenvolvimentista do Autismo}

A perspectiva desenvolvimentista traz uma nova forma de entendimento dos prejuízos do autismo sem cair na oposição linguagem/social, mostrando ao contrário como estas capacidades humanas estão relacionadas, ou melhor, como a linguagem se desenvolve a partir da interação social. Serão apresentadas aqui três elaborações teóricas iniciais de importantes autores na área do autismo: Trevarthen (Trevarthen \& cols., 1998), Hobson (2002) e Dawson (Dawson \& Galpert, 1986; Dawson \& Lewy, 1989). Embora diferentes, suas formulações têm em comum um ponto de partida biológico e a análise do desvio do processo de desenvolvimento.

Trevarthen e colaboradores (1998) consideram que o autismo deve ser um distúrbio do mecanismo inato para se relacionar com pessoas e acreditam que a linguagem, e os processos de pensamento baseados na linguagem, são afetados nos autistas porque as funções de atenção e intersubjetividade, mais profundas e com desenvolvimento precoce, estão prejudicadas.

A partir da observação de filmes, estes autores afirmam que bebês nascem com a capacidade de se comunicar com os sentimentos, interesses e objetivos de outras pessoas. Ainda muito pequenos, eles reconhecem pessoas e gostam de conversar com elas. Esta primeira fase do relacionamento intersubjetivo, que aparece logo após o nascimento, é a fase da intersubjetividade primária. Ela consiste de protoconversações que envolvem uma alternância rítmica de turno de atos expressivos. Mãe e bebê apresentam expressões e percepções ativas de emoções, em interações face-a-face. A mãe usa o manhês (motherese), toca e apresenta ao bebê expressões com a face e as mãos, enquanto o bebê responde brincando com afeto, imita e provoca imitações pela mãe.

De acordo com Trevathen e colaboradores (1998), o autismo é uma condição que afeta o desenvolvimento desse sistema interativo pré-lingüístico inato, devido a uma falha, provavelmente no primeiro mês do desenvolvimento do embrião, em uma região do cérebro por eles chamada de Formação de Motivo Intrínseca (Intrinsic Motive Formation). Desta maneira, a falta de respostas expressivas e de orientação, por parte do bebê autista, tenderia a cortá-lo das transações comunicativas e emocionais dos outros. A raíz do problema seria, então, um déficit específico na percepção e na motivação com relação a pessoas. E isto impediria a passagem para a segunda fase do relacionamento intersubjetivo, a da intersubjetividade secundária que se desenvolve por volta dos 9 meses de idade e é caracterizada pela proto-linguagem. Nesta fase, as interações mãe-bebê passam a incluir eventos e objetos que são motivo de interesse. O bebê, por exemplo, olha para a mãe, mostra um brinquedo e vocaliza, enquanto a mãe olha para o brinquedo, ouve a verbalização e pega o brinquedo. Aqui, o bebê passa a combinar vocalizações com gestos para fazer declarações, observações, orientações; a compartilhar interesse em eventos e objetos. É a atenção compartilhada cuja ausência é um dos marcadores do autismo.

Os autores concluem que o desenvolvimento humano é essencialmente interpessoal; que a vida humana depende da intersubjetividade. O problema central na comunicação da criança autista estaria relacionado à falta de reconhecimento das funções interpessoais da linguagem, a uma falha específica na compreensão de como ter reciprocidade com outras pessoas, e não a sistemas cognitivos envolvidos na compreensão e expressão de palavras. As falhas de linguagem seriam um efeito secundário.

3 Embora o termo "mãe" abranja o sentido de "cuidador", ele será privilegiado aqui tendo em vista que a mãe costuma ser o principal cuidador do bebê. 
Adotando também um enfoque intersubjetivo, Hobson (2002) acredita que subjacente ao autismo está uma falta de comportamento inato para a coordenação com o comportamento social das outras pessoas. Faltaria ao bebê que irá desenvolver um quadro autista, o engajamento pessoa-a-pessoa, as habilidades para a conexão emocional e a comunicação não-verbal, isto é, a responsividade emocional. E assim como Trevarthen e colaboradores, Hobson também considera que é o engajamento social que proporciona os fundamentos da linguagem.

De acordo com Hobson (2002), o que caracteriza o humano é o simbolizar, e são as relações interpessoais que promovem a compreensão e uso de símbolos. Mas, ele parte do princípio que alguns componentes do funcionamento mental são inatos e que o desafio é descobrir quais habilidades são subjacentes a outras habilidades de maneira a refazer o processo de desenvolvimento. Em um primeiro momento, a nível filogenético, teria sido uma mudança na natureza do engajamento social dos primatas, que envolve mudanças sutis porém profundas nas interações face-a-face, que teria levado aos tipos de pensar e de linguagem representativos dos seres humanos. Em um segundo momento, a nível ontogenético, Hobson se refere a uma linguagem universal do corpo, isto é inata, que estaria na base para o engajamento interpessoal e o simbolizar. Ele observa que os bebês estão aptos para perceber e reagir ao comportamento e expressões das outras pessoas, e a tomar seu papel na dança comunicativa do intercâmbio interpessoal. Uma de suas observações mais importantes parece ser que, desde os primeiros meses de vida, os bebês se relacionam com as pessoas como pessoas, isto é, eles fazem mais do que apresentar padrões coordenados de comportamento com outras pessoas; eles estão emocionalmente conectados a elas. Seria através desta conectividade emocional que o bebê descobriria o tipo de coisa que uma pessoa é, e como conseqüência aprenderia a diferenciar pessoas de coisas. Como exemplos, podem ser citadas as habilidades do bebê de seis semanas de idade para manter contato ocular e com isso manter o engajamento interpessoal. Além disso, com dez semanas de vida, o bebê é capaz de reagir às expressões emocionais da mãe com estados emocionais próprios.

Tudo isso faria parte da fase de subjetividade primária de Trevarthen. Na fase seguinte, a da intersubjetividade secundária, o bebê passaria a ser sensível à relação de uma pessoa com um objeto. Aqui, ele não apenas se interessaria e responderia ao que o outro faz com objetos mas, também, ao que o outro sente, caracterizando um engajamento emocional com as atitudes dos outros. É neste momento que se desenvolve a capacidade de simbolização. A partir do desenvolvimento da atenção compartilhada, torna-se possível o engajamento em jogos que incorporam aspectos importantes da comunicação e preparam o caminho para a linguagem.

Na visão de Hobson (2002), no autismo, haveria uma falta de responsividade emocional e, portanto, uma falta de engajamento intersubjetivo. Desta maneira, todo o desenvolvimento acima descrito ficaria prejudicado. A falha no relacionamento eno compartilhar levariam ao empobrecimento da vida imaginativa assim como tornariam o empreendimento da linguagem sem sentido.

Uma terceira posição desenvolvimentista é a de Dawson que considera o debate sobre a primazia de prejuízos afetivos versus cognitivos sem sentido, já que os comportamentos prejudicados nos autistas têm tanto funções socioemocionais como cognitivas. Dawson e Galpert (1986) consideram que os prejuízos característicos do autismo envolvem as capacidades iniciais expressivas e receptivas que são a base para o desenvolvimento da interação social que permite o desenvolvimento da comunicação não-verbal, percursora da comunicação verbal. Em outro trabalho, Dawson e Lewy (1989) apresentam uma proposta original de compreensão do autismo. Apoiados em pesquisas na área da fisiologia, os autores pretendem apresentar um quadro teórico inicial e levantar algumas hipóteses sobre as relações entre nível de ativação do bebê, déficits de atenção, perfil de desenvolvimento e prejuízo do desenvolvimento socioemocional. Em síntese, sua posição é que bebês autistas têm um baixo limiar de sensibilidade para estímulos novos e estímulos imprevisíveis, como o comportamento de seres humanos. Como conseqüência, as pessoas se tornam super-estimuladoras e aversivas para o bebê provocando respostas de evitação que afetarão a formação inicial do apego a pessoas, a expressão das emoções e a coordenação interpessoal da expressão afetiva. No final, os autores apresentam uma proposta de intervenção utilizando a imitação do comportamento da própria criança autista como estratégia para facilitar a sua atenção social e aumentar a responsividade social geral. Essa proposta de intervenção foi posteriormente mais elaborada de maneira a incluir a promoção de outras habilidades consideradas como andaime para o desenvolvimento da linguagem : o contato ocular, a atenção a estímulos sociais e o desenvolvimento da noção de contingência das ações, a imitação e a atenção compartilhada (Klinger \& Dawson, 1992).

As três propostas apresentadas têm em comum a adoção de uma perspectiva desenvolvimentista que consiste em analisar o processo de desenvolvimento típico e procurar identificar as falhas ou desvios que ocorrem no desenvolvimento da criança autista. Elas procuram mostrar como o produto final - a interação social e a comunicação - derivam conjuntamente de um processo de construção a partir de um ponto de partida biológico. Em suas análises, são enfatizadas a sensibilidade/ responsividade expressividade emocionais iniciais e os processos 
intersubjetivos subseqüentes que possibilitam o desenvolvimento da comunicação não-verbal e verbal. No caso do autismo, tendo em vista uma falha biológica inicial, todo o processo de desenvolvimento será desvirtuado.

Os três autores propõem, no caso do autismo, uma falha emocional inicial, isto é, uma falha nas capacidades expressivas e receptivas inatas. Sem estas capacidades, o processo de intersubjetividade primária que envolve as primeiras interações face-a-face mãe-bebê não pode ocorrer, ou ocorre de forma limitada e desvirtuada. Conseqüentemente, o processo de intersubjetividade secundária, que envolve agora uma relação tripartite mãe-bebê-objeto, também será prejudicada. E este último processo é fundamental porque é através da atenção compartilhada, que o caracteriza, que se desenvolve a capacidade de simbolizar base do desenvolvimento da comunicação não-verbal e, posteriormente, verbal.

Esta perspectiva pode ter como uma de suas conseqüências a dissolução da oposição linguagem x social. A linguagem passa a ser vista como comunicação - verbal e não-verbal - que se desenvolve a partir da interação mãebebê - intersubjetividade primária e secundária. Outra conseqüência possível diz respeito ao argumento que linguagem e social são, por definição, a mesma coisa. Se considerarmos que a sensibilidade social é um pré-requisito para o início das relações intersubjetivas, então a capacidade de relacionamento social seria anterior ao desenvolvimento da linguagem/comunicação. Na verdade, a partir dos pressupostos do enfoque desenvolvimentista, seria possível afirmar que a oposição ou identidade, entre linguagem e social, é um falso problema, ou uma questão mal colocada. Oenfoque trata de um contínuo que se inicia com a sensibilidade social e se prolonga até a aquisição da comunicação verbal.

Esta ênfase no processo de desenvolvimento pode ser vista como representando uma perspectiva construtivista que se opõe à perspectiva racionalista apresentada por aqueles que adotam uma posição cognitivista.

\section{Conclusão}

Na introdução deste trabalho foi comentada a imprecisão do conceito de autismo, dada a heterogeneidade dos quadros clínicos apresentados pelas crianças portadoras de autismo e a existência de dois enfoques teóricos predominantes. Por um lado, o enfoque cognitivista que, no passado, defendeu a linguagem como déficit primário no autismo e, hoje, defende um prejuízo na teoria da mente. Por outro lado, o enfoque desenvolvimentista que, hoje, defende um prejuízo inato da afetividade, isto é, da sensibilidade, responsividade e expressividade emocional que impossibilita o desenvolvimento do relacionamento social e que, no passado, argumentou ser o prejuízo social o prejuízo primário no autismo. Foi também comentada a importância de se rever o debate ocorrido nas décadas de 1970/80 sobre o prejuízo primário, de maneira a procurar esclarecer os conceitos de social e linguagem, já que gestos são vistos tanto como interação social quanto como comunicação, e avaliar a possibilidade de dissolução das oposições teóricas subjacentes - enfoque cognitivista $\mathrm{x}$ enfoque desenvolvimentista. $\mathrm{O}$ objetivo final seria uma tentativa de iniciar uma reflexão a respeito da relevância do esclarecimento dos pressupostos epistemológicos e das implicações de diferentes enfoques teóricos do autismo, para a busca de uma etiologia e para a intervenção.

A discussão apresentada na parte relativa ao debate sobre o prejuízo primário pode parecer confusa. Autores de diferentes posições concordam quanto a uma base inata no autismo e quanto às características comportamentais nos déficits sociais e de linguagem. Contudo, alguns defendem um déficit primário em uma área mas reconhecem déficits básicos na outra. Rutter (1978), por exemplo, defende um prejuízo primário na linguagem mas admite déficits sociais muito precoces como a falta de respostas às emoções dos outros. Além disso, outros argumentam a favor de determinado prejuízo primário mas admitem que o oposto também é possível. Wing (Shah \& Wing, 1986), por exemplo, admite déficits quanto à percepção de pessoas e concebe isto como um déficit cognitivo. Mas aceita a possibilidade de anormalidades sociais estarem na base dos problemas de cognição social. Outros, ainda, afirmam não haver separação entre linguagem e social considerando, como Olley (1985) e Lord (1985), a linguagem como um ato social. A discussão parece, assim, inconclusiva.

Um melhor entendimento deste debate requer a explicitação e análise dos pressupostos epistemológicos e visões de sujeito sustentadas por ambas as posições. Para tanto, serão comparados, a partir de suas concepções de inato, o enfoque cognitivista - a partir dos argumentos do prejuízo da linguagem - e o enfoque desenvolvimentista concebido como um prolongamento dos argumentos de prejuízo da interação social.

O enfoque cognitivista, ao considerar a capacidade da linguagem como uma função cognitiva, um módulo da mente, adere a uma visão objetivista/racionalista de sujeito - uma visão naturalista. Segundo esta visão, o sujeito é um ser natural dotado de certas capacidades psicológicas dadas desde o início. A racionalidade, a intencionalidade, a consciência e os processos psicológicos básicos como atenção, memória, percepção e linguagem (vista como uma forma de representação), que diferenciam os seres humanos de outras espécies, são considerados inatos (Baker \& Hacker, 1984). 
O enfoque desenvolvimentista não descarta o inato mas procura analisar sua articulação com as experiências sociais, considerando sua participação na construção das capacidades específicas dos humanos. Desta maneira, adere a uma visão construtivista/pragmática de sujeito - uma visão social. Isto não significa afirmar que não há nada de inato; significa considerar que o que possa haver de inato possibilita certas construções. A linguagem é concebida como um forma de ação; como uma prática social. Em outras palavras, dada uma base inata, é no contexto de interações sociais que são construídas as capacidades especificamente humanas (Vygotsky, 1984; Wittgenstein, 1958). O foco está no processo de construção/desenvolvimento.

No caso do autismo, de acordo com o enfoque cognitivista, por ter o módulo da linguagem prejudicado, a criança não é capaz de se comunicar; não pode interagir socialmente. Há aqui uma perspectiva determinista. As diferentes características de uma criança autista são vistas como sendo naturais e os diferentes quadros clínicos, apresentados por diferentes crianças, como se devendo, principalmente, a diferentes prejuízos ou etiologias de cunho biológico. Segundo o enfoque desenvolvimentista, dada a falta inata de sensibilidade, responsividade e expressividade emocional/afetiva/social, a criança autista não é capaz de intersubjetividade primária; não é capaz de estabelecer as proto-conversações, características das interações face-a-face. Como conseqüência, ela não será capaz de desenvolver/ construir a fase de intersubjetividade secundária, a da protolinguagem, que envolve a relação tripartite mãe-bebê-objeto. Seria esta a razão pela qual a criança autista não desenvolve a atenção compartilhada e a simbolização - a comunicação não-verbal, precursora da comunicação verbal. Aqui, as características comportamentais de uma criança autista devem ser avaliadas dentro de um contexto social, e os diferentes quadros clínicos de diferentes crianças como sendo conseqüência da conjunção de diferentes etiologias e diferentes histórias de relacionamento social. Para dar conta de determinado quadro comportamental, o foco estará sempre na avaliação do contexto de interações. Por exemplo, no caso de uma criança que apresente estereotipias motoras, isto pode ser visto como biologicamente determinado - visão objetivista/cognitivista - ou como conseqüência de um contexto, dada uma especificidade biológica - visão construtivista/desenvolvimentista. A criança pode apresentar estereotipias em certas circunstâncias provocadoras de ansiedade mas não em outras.

Os argumentos de Rutter (1976) e Wing (1980), em defesa de um prejuízo primário da linguagem, poderiam ser respondidos da seguinte maneira, a partir de uma perspectiva construtivista/desenvolvimentista: quando Rutter observa que o atraso na fala é uma condição invariável no autismo, e por isso a linguagem deve ser vista como prejuízo primário, ele está invocando a universalidade do déficit e, ao adotar o cognitivismo, pressupondo a separação entre linguagem e social. Mas a visão construtivista/desenvolvimentista pode dar conta dessa universalidade invocando o déficit social, por conceber a linguagem como envolvendo uma atividade social - forma de ação - e não uma atividade cognitiva forma de representação. Ou seja, o déficit de linguagem é universal no autismo porque o déficit social que permite seu desenvolvimento, é universal. Quanto a Wing, quando ela argumenta que o isolamento é inferido a partir de problemas de linguagem e de comunicação não-verbal, que interferem com intercâmbios sociais, está também adotando o cognitivismo e fazendo a mesma separação entre linguagem e social, sem admitir a comunicação como uma atividade social. De acordo com a visão desenvolvimentista, a partir da intersubjetividade secundária, intercâmbios sociais são intercâmbios comunicativos. O que mais poderiam ser?

Estes diferentes enfoques representam diferentes concepções de autismo, com conseqüências tanto para a busca de uma etiologia quanto para a intervenção. A procura de uma etiologia nunca é feita indutivamente mas sempre a partir de um enfoque teórico. No caso do enfoque objetivista, a tendência será procurar correspondências biunívocas entre o biológico e o comportamento, correndo-se o risco de não dar conta de todo o quadro comportamental. No caso do enfoque construtivista, a tarefa se torna extremamente complexa dada a multiplicidade de possibilidades de observações. Quanto à intervenção, o enfoque objetivista tenderá a enfocar características comportamentais isoladamente, enquanto o construtivista procurará estabelecer precursores com o objetivo de retraçar o caminho não percorrido. No caso de uma criança de três anos de idade sem fala e sem interação social, por exemplo, procurar-se-à estabelecer comportamentos característicos da intersubjetividade primária e secundária - contato ocular, prestar atenção aos outros, observar a contingência das ações, imitação, atenção compartilhada - mesmo que a idade cronológica tenha ficado há muito para trás.

Estas observações não pretendem dar conta, e muito menos 'resolver', as questões envolvidas neste transtorno do desenvolvimento. Inúmeros autores importantes têm refletido e pesquisado sobre o autismo. $\mathrm{O}$ volume de conhecimentos alcançados é significativo e a qualidade das análises cada vez mais fina. Mas o mistério permanece. $\mathrm{O}$ objetivo deste artigo foi apenas iniciar uma reflexão a respeito da importância de se ter claro o enfoque teórico adotado, assim como de suas implicações. Esta reflexão demanda sem dúvida um aprofundamento. 


\section{Referências}

American Psychiatric Association (1995). Manual diagnóstico e estatístico de transtornos mentais ( $4^{\mathrm{a}}$ ed.) (D. Batista, Trad.). Porto Alegre: Artes Médicas.

Baker, G. P. \& Hacker, P. M. S. (1984). Language, sense and nonsense. A critical investigation into modern theories of language. Oxford: Basil Blackwell.

Baron-Cohen, S. (2000). Theory of mind and autism: A fifteen year review. Em S. Baron-Cohen, H. Tager-Flusberg \& D. J. Cohen (Orgs.), Understanding other minds: Perspectives from developmental cognitive neuroscience $\left(2^{\text {nd }}\right.$ ed., pp. $3-$ 20). London: Oxford University Press.

Bartak, L., Rutter, M. \& Cox, A. (1975). A comparative study of infantile autism and specific developmental receptive language disorder: I. The children. British Journal of Psychiatry, 126, 127-145.

Cairns, R. B. (1986). Social development: Recent theoretical trends and relevance for autism. Em E. Schopler \& G. B. Mesibov (Orgs.), Social behavior in autism (pp.15-33). New York: Plenum Press.

Camaioni, L., Perucchini, P., Muratori, F. \& Milone, A. (1997). Brief report: A longitudinal examination of the communicative gestures deficit in young children with autism. Journal of Autism and Developmental Disorders, 27, 6, 715725.

Dawson, G. \& Galpert, L. (1986). A developmental model for facilitating the social behavior of autistic children. Em E. Schopler \& G. B. Mesibov (Orgs.), Social behavior in autism (pp. 237-261). New York: Plenum Press.

Dawson, G. \& Lewy, A. (1989). Arousal, attention, and the socioemotional impairments of individuals with autism. Em G. Dawson (Org.), Autism: Nature, diagnosis and treatment (pp. 49-74). New York: Guildford Press.

Eisenberg, L. \& Kanner, L. (1956). Early infantile autism, 1943-55. American Journal of Orthopsychiatry, XXVI, 3, 556-566.

Frith, U. (1997). Autism. Scientific American Mysteries of the Mind, Special Issue, 7(1), 92-98.

Garfin, D.G. \& Lord, C. (1986). Communication as a social problem in autism. Em E. Schopler \& G. B. Mesibov (Orgs.), Social behaviorin autism (p. 133-151). New York: Plenum Press.

Green, L., Fein, D., Joy, S. \& Waterhouse, L. (1995). Cognitive functioning in autism: An overview. Em E. Schopler \& G.B. Mesibov (Orgs.), Learning and cognition in autism (pp. 13-31). New York: Plenum Press.

Hermelin, B. \& O'Connor, N. (1985). Logico-affective states and nonverbal language. Em E. Schopler \& G. B.Mesibov (Orgs.), Communication problems in autism. (p. 283-310). New York: Plenum Press.

Hobson, P. (2002). The cradle of thought. London: Macmillan.

Kanner, L. (1943). Autistic disturbances of affective contact. Nervous Child, 2, $217-$ 250.

Klinger, L.G. \& Dawson, G. (1992). Facilitating early social and communicative development in children with autism. Em S. F. Warren \& J. Reichle (Orgs.), Causes and effects in communication and language intervention (pp. 157-186). Baltimore, Mar: Paul H. Brookes.

Lord, C. (1985). Autism and the comprehension of language. Em E. Schopler \& G.B. Mesibov (Orgs.), Communication problems in autism (pp. 257-281). New York: Plenum Press.

Mundy, P. \& Crowson, M. (1997). Joint attention and early social communication: Implications for research on intervention with autism. Journal of Autism and Developmental Disorders, 27, 6, 653-676.

Mundy, P. \& Sigman, M. (1989). Specifying the nature of the social impairment in autism. Em G. Dawson (Org.), Autism. Nature, diagnosis, and treatment (pp. 321). New York: The Guilford Press.
Olley, J. G. (1985). Social aspects of communication in children with autism. Em E. Schopler \& G. B. Mesibov (Orgs.), Communication problems in autism (pp. 311-328). New York: Plenum Press.

Rapin, I. (1996). Historical data. Em I. Rapin (Org.), Preschool cbildren with inadequate communication. Developmental language disorder, autism, low IQ (pp. 58-97). London: Mac Keith Press.

Richer, J. (1976). The partial noncommunication of culture to autistic children - An application of human ethology. Em M. Rutter \& E. Schopler (Orgs.), Autism a reappraisal of concepts and treatment (pp. 47-61). New York: Plenum Press.

Rutter, M. (1968). Concepts of autism: A review of research. Journal of Child Psychology and Psychiatry and Allied Disciplines, 9, 1-25.

Rutter, M. (1976). Language disorder and infantile autism. Em M. Rutter \& E. Schopler (Orgs.), Autism a reappraisal of concepts and treatment (pp. 85-104). New York: Plenum Press.

Rutter, M. (1978). Diagnosis and definition of childhood autism. Journal of Autism and Developmental Disorders, 8, 139-161.

Rutter, M. \& Schopler, E. (1988). Autism and pervasive developmental disorders: Concepts and diagnostic issues. Em E. Schopler \& G. B. Mesibov (Orgs.), Diagnosis and assessment in autism (pp. 15-36). New York: Plenum Press.

Schopler, E. \& Mesibov, G.B. (1986). Introduction to social behavior in autism. Em E. Schopler \& G. B. Mesibov (Orgs.), Social behavior in autism (pp. 1-11). New York: Plenum Press.

Shah, A. \& Wing, L. (1986). Cognitive impairments affecting social behavior in autism. Em E. Schopler \& G. B. Mesibov (Orgs.), Social behavior in autism (pp. 153-169). New York: Plenum Press.

Stone, W. L., Ousley, O.Y., Yoder, P. J., Hogan, K. L. \& Hepburn, S. L. (1997). Nonverbal communication in two- and three-year-old children with autism. Journal of Autism and Developmental Disorders, 27, 6, 677-696.

Trevarthen, C., Aitken, K., Papoudi, D. \& Robarts, J. (1998). Children with autism. Diagnosis and interventions to meet their needs ( $2^{\text {nd }} \mathrm{ed}$.). London: Jessica Kingsley.

Vygotsky, L. S. (1984). A formação social da mente. O desenvolvimento de processos psicológicos superiores. São Paulo: Martins Fontes.

Walters, A., Barrett, R. P. \& Feinstein, C. (1990). Social relatedness and autism: Current research, issues, directions. Research in Developmental Disabilities, 11, 303-326.

Waterhouse, L., Wing, L. \& Fein, D. (1989). Re-evaluating the syndrome of autism in the light of empirical research. Em G. Dawson (Org.), Autism. Nature, diagnosis, and treatment (pp. 263-281). New York: The Guilford Press.

Wing, L. (1980). Diagnosis, clinical description and prognosis. Em L. Wing (Org.), Early childhood autism. Clinical, educational and social aspects (pp. 15-48). Oxford: Pergamon Press.

Wing, L. (1981). Language, social, and cognitive impairments in autism and severe mental retardation. Journal of Autism and Developmental Disorders, 11, 1, 31-44.

Wing, L. (1988). The continuum of autistic characteristics. Em E. Schopler \& G.B. Mesibov (Orgs.), Diagnosis and assessment in autism (pp. 91-110). New York: Plenum Press.

Wing, L. \& Gould, J. (1979). Severe impairments of social interaction and associated abnormalities in children: Epidemiology and classification. Journal of Autism and Developmental Disorders, 9, 1, 11-29.

Wittgenstein,L. (1958). Philosophical investigations. Oxford: Basil Blackwell.

Recebido: 29/04/2003

$1^{a}$ Revisão: 01/07/2003

Aceite Final: 04/07/2003

Sobre a autora

Carolina Lampreia é Doutora em Psicologia Clínica pela Pontifícia Universidade Católica do

Rio de Janeiro e Professora do Departamento de Psicologia da mesma instituição. 